\title{
Pelatihan Pembuatan Lampu Hias Akrilik 3D LED Lamp Untuk Meningkatkan Pendapatan Bagi Pemuda Tunakarya Kelurahan Bentiring
}

\author{
Yanolanda Suzantry Handayani ${ }^{1}$, Adhadi Kurniawan ${ }^{2}$, Fitrilina ${ }^{3}$ \\ ${ }^{123}$ Fakultas Teknik, Universitas Bengkulu \\ E-mail: e-mail: yanolanda@unib.ac.id
}

Article History:
Received: September
Revised: Oktober
Accepted: November
Available online : Desember

Kata Kunci:

Akrilik, Lampu Hias, LED

Lamp, Pemuda,

Pengangguran

\begin{abstract}
Abstrak :
Bahan material yang digunakan untuk lampu hias seperti bahan kaca, dan akrilik. Kaca atau papan akrilik dapat terlihat menarik dan menawan maka dipasang lampu led agar dapat mengeluarkan cahaya yang indah. Pekerjaan yang dilakukan para warga di RT.10 juga bermacam-macam ada yang sebagai guru, pedagang keliling, pedagang warung, buruh harian, buruh bangunan, dan ojek online. Seiring dengan pertambahan penduduk di RT.10 sehingga menyebabkan angka pengangguran di RT.10 meningkat apalagi pada musim pandemi saat ini, yang mana warga di Kota Bengkulu diminta berdiam diri di rumah sehingga banyak pemudapemudanya menjadi pengangguran dan tidak bisa mencari nafkah untuk biaya hidup. Kegiatan pengabdian ini terdiri dari tiga sesi yaitu pemberian materi tentang pengertian lampu hias, papan akrilik, dan bahan serta alat untuk membuat lampu hias, sesi kedua praktek langsung merakit lampu hias 3D, dan sesi terakhir yaitu evaluasi kegiatan yang berisikan tentang mengisi angket penilaian peserta tentang penyampaian materi dan kegiatan merakit lampu.
\end{abstract}




\section{Pendahuluan}

Lampu merupakan salah satu produk yang penting dalam kehidupan manusia. Dengan adanya lampu manusia dapat terus beraktivitas tanpa perlu bergantung pada sumber cahaya alami, yaitu matahari. Seiring perkembangan lampu tidak lagi hanya menjadi sumber cahaya, tetapi juga sekaligus menjadi elemen dekorasi. Lampu tidak lagi dipilih hanya berdasarkan kemampuannya untuk menerangi ruangan, tetapi juga penampilan dari lampu tersebut. Oleh karena itu desain lampu hias semakin berkembang dan maju (Claudia \& Setiawan, 2017)

Seiring dengan perkembangan teknologi, banyak material yang dapat dipilih untuk membuat lampu hias. Bahan material yang digunakan seperti bahan benang, kayu, bamboo, plastic, kaca, dan akrilik. Bahan material tersebut ada kelebihan dan kekurangannya. Pada lampu hias menggunakan bahan dari kaca atau papan akrilik yang bening ini dapat diukir sesuai dengan keinginan seperti gambar karakter atau karikatur. Kaca atau papan akrilik dapat terlihat menarik dan menawan maka dipasang lampu agar dapat mengeluarkan cahaya yang indah. Lampu tersebut dipasang menggunakan lampu Led Strip yang bermacam warnanya sesuai dengan warna yang kita inginkan.

Muara Bangkahulu adalah sebuah kecamatan di Kota Bengkulu, yang memiliki desa atau kelurahan berjumlah 7 kelurahan dengan luas wilayas seluas $23,96 \mathrm{~km}^{2}$ dan jumlah penduduknya sebanyak 2.403 jiwa, salah satunya adalah kelurahan Bentiring, Kelurahan Bentiring terdiri dari Rukun Warga (RW) sebanyak $3 \mathrm{RW}$ dan Rukun Tetangga (RT) terdiri dari RT.01 sampai dengan RT.13. Salah satu Rukun Tetangga yang ada di RW.03 adalah RT.10, RT.10 ini berada di Jl.Korpri Raya (Sejarah Kota Bengkulu - Website Resmi Profil| Pemerintah Kota Bengkulu, 2020). Yang mana jenjang status sosialnya berbeda-beda ada yang menengah ke bawah, sedang dan mampu. Pekerjaan yang dilakukan para warga di RT.10 juga bermacam-macam ada yang sebagai PNS, Guru, Dosen, Pedagang keliling, pedagang warung, buruh harian, buruh bangunan, dan ojek online. Status pendidikan di RT.10 juga bermacammacam ada yang hanya tamatan SD (Sekolah Dasar), SMP (Sekolah Menengah Pertama), SMA (Sekolah Menengah Atas), Strata 1, dan Strata 2. 
Seiring dengan pertambahan penduduk di RT.10 sehingga menyebabkan angka pengangguran di RT.10 meningkat apalagi pada musim Covid 19 (Coronavirus Disease 2019) ini, yang mana warga di Kota Bengkulu disuruh berdiam diri di rumah sehingga banyak pemuda-pemudanya menjadi pengangguran dan tidak bisa mencari nafkah untuk biaya hidup. Selain itu kebiasan pemuda-pemuda yang pengangguran di RT.10 ini sering berkumpul hal yang tidak bermanfaat salah satu contohnya adalah menyabung ayam, kebut-kebutan motor, dan duduk-duduk sambil merokok.

Berdasarkan dari latar belakang diatas maka judul dari artikel ini adalah Pelatihan Pembuatan Lampu Hias Akrilik 3D Led Lamp Untuk Meningkatkan Pendapatan Pemuda Tunakarya Kelurahan Bentiring. Dan dilakukannya pembinaan dan pengajaran Ilmu Pengetahuan dan Teknologi yang dapat menambah pengetahuan yang bermanfaat kepada pemuda-pemuda di RT.10.

\section{Metode}

Beberapa metode pengabdian yang digunakan adalah :

1. Pemberian materi dengan metode sosialisasi yaitu pemberian materi tentang pengertian lampu hias, papan akrilik, dan bahan serta alat untuk membuat lampu hias, lalu memperkenalkan bahan dan alat yang digunakan pada pembuatan lampu hias akrilik 3D.

2. Pelatihan pembuatan lampu hias 3D LED yaitu dengan metode praktik langsung membuat lampu hias.

3. Evaluasi kegiatan yaitu dengan metode observasi menggunakan instrumen pertanyaan mengenai apakah materi yang disampaikan oleh para tenaga pengajar sudah sangat jelas dan mudah difahami dan dimengerti, selain itu dengan membagikan angket pertanyaan melihat sebatas mana kemapuan peserta menguasai dan mempraktekkan pembuatan Lampu Hias Akrilik 3D Led, agar Lampu Hias Akrilik 3D Led ini dapat di pasarkan dan dijual sehingga dapat meningkatkan pendapatan pemuda Tunakarya Di Jalan Korpri Rt. 10 Kelurahan Bentiring Kecamatan Muara Bangkahulu Kota Bengkulu. Hasil angket pertanyaan akan diolah menggunakan Microsoftexcel 2016. 


\section{Hasil}

Berdasarkan metode pengabdian yang digunakan yaitu sosialisasi, pelatihan dan pengolahan data menggunakan microsoftexcel 2016, hasil pengabdian berupa lampu hias akrilik 3D led yang sudah dirangkai dan dapat dijelaskan berdasarkan tampilan gambar-gambar berikut :

Tabel 1. Alat yang digunakan Untuk Pembuatan

Lampu Hias Akrilik 3D Led Lamp

\begin{tabular}{cll}
\hline No & \multicolumn{1}{c}{ Bahan } & Jumlah \\
\hline 1 & Bor Kayu & 1 Buah \\
\hline 2 & Mini drill bor mini & 1 Buah \\
\hline 3 & Cutter Acrylic & 1 Buah \\
\hline 4 & Penggaris siku-siku & 1 Buah \\
\hline 5 & Solder & 1 Buah \\
\hline 6 & Dudukan Solder & 1 Buah \\
\hline 10 & Toolkit & 1 Buah \\
\hline
\end{tabular}

Tabel 2. Bahan yang digunakan Untuk Pembuatan Lampu Hias Akrilik 3D Led

\begin{tabular}{cll}
\hline No & \multicolumn{1}{c}{ Bahan } & \multicolumn{1}{c}{ Jumlah } \\
\hline 1 & Papan 40cm x 60cm & 1 Keping \\
\hline 2 & Windou Film $100 \mathrm{~cm} \mathrm{x} 50 \mathrm{~cm}$ & 1 Lembar \\
\hline 3 & Akrilik Bening $60 \mathrm{~cm} \mathrm{x} 15 \mathrm{~cm}$ & 1 Keping \\
\hline 4 & Kaca $60 \mathrm{~cm}$ x $65 \mathrm{~cm}$ & 1 Keping \\
\hline 5 & Kertas Pembungkus $45 \mathrm{~cm} \mathrm{x} 400 \mathrm{~cm}$ & 1 Lembar \\
\hline 6 & Doble Tipe Kayu & 1 gulung \\
\hline 7 & Kabel Listrik Merah-Hitam & 1 meter \\
\hline 8 & Lampu Led Meteran & $30 \mathrm{~cm}$ \\
\hline 9 & Lem Aibon Kaleng Sedang & 2 sendok \\
\hline 10 & Adaptor 12 Volt 1 A & 1 pcs \\
\hline 11 & Timah Solder & $30 \mathrm{~cm}$ \\
\hline 12 & Sabun Kaca & $1 / 4$ gelas \\
\hline 13 & Saklar On Off & 1 pcs \\
\hline
\end{tabular}


Langkah-Langkah Pembuatan Lampu Hias Akrilik 3D Led :

1. Siapkan 1 keping Papan dengan ukuran $10 \mathrm{~cm}$ x $20 \mathrm{~cm}$.

2. Potong tengah-tengah papan dengan bentuk seperti gambar 1 di bawah ini.

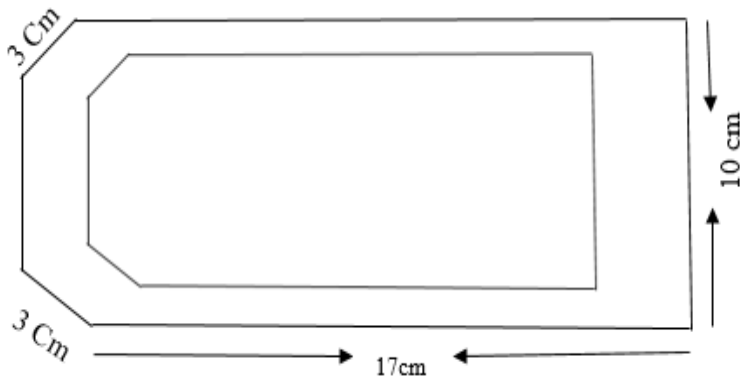

Gambar 1. Hasil Pemotongan Papan

3. Siapkan dudukan papan dengan bentuk gambar 2 dibawah ini

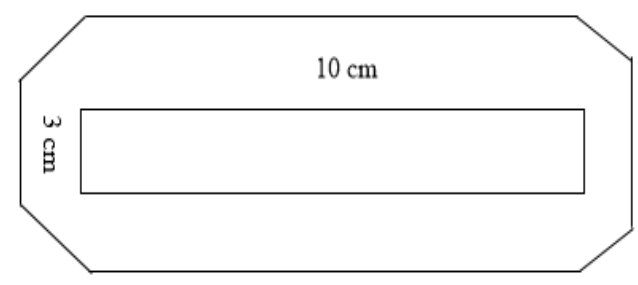

Gambar 2. Dudukan Papan

4. Bungkus semua papan pada kertas pembungkus

5. Papan yang telah dibentuk dan dudukannya disatukan sehingga menjadi pada gambar 3 di bawah ini.

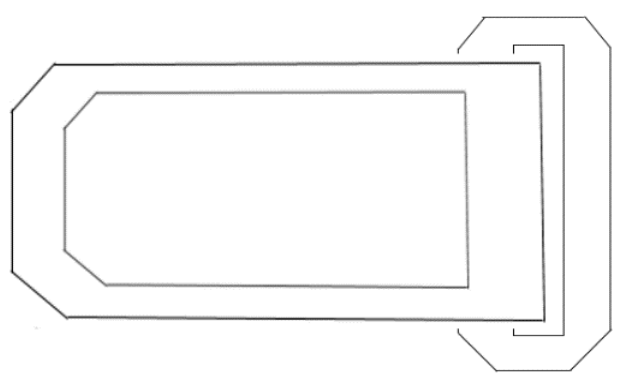

Gambar 3. Dudukan Papan 
6. Siapkan cermin dan kaca atau akrilik sesuai dengan ukuran papan pada langkah ke dua.

7. Lapisi kaca atau papan akrilik menggunakan windou film, sebelum ditempel menggunakan windou film terlebih dahulu permukaan kaca atau papan akrilik disemprot menggunakan air sabun, agar mendapatkan hasil tempelan yang rapi.

8. Papan yang dibentuk dan papan dudukan yang sudah dibungkus menggunakan kertas pembungkus bagian bawahnya di bor untuk lubang pemasangan kabel merah hitam penghubung.

9. Masukkan kabel penghubung ke lubang papan yang dibentuka dan papan dudukan.

10. Solder antara ujung kabel penghubung yang warna hitam kekutub negatif dan warna merah kekutub positif ke ujung lampu Led meteran.

11. Tempel sekeliling papan yang sudah dibentuk dengan lampu Led metereran melingkar mengikuti potongan tengahnya.

12. Tempel cermin dan Kaca (akrilik) menggunakan dobletip ke papan yang sudah dibentuk.

13. Pasang saklar On/Off ke kabel Hitam Merah lalu hubungkan adaptor/power suplay 12 volt $1 \mathrm{~A}$.

14. Lampu Hias Akrilik 3D Led sudah siap dipasarkan atau digunakan.

Untuk hasil evaluasi kegiatan beruapa angket pertanyaan mengenai apakah materi yang disampaikan oleh para tenaga pengajar sudah sangat jelas dan mudah difahami dan dimengerti, selain itu dengan membagikan angket pertanyaan melihat sebatas mana kemapuan peserta menguasai dan mempraktekkan pembuatan Lampu Hias Akrilik 3D Led, agar Lampu Hias Akrilik 3D Led ini dapat di pasarkan dan dijual sehingga dapat meningkatkan pendapatan pemuda Tunakarya di Jalan Korpri Rt. 10 Kelurahan Bentiring Kecamatan Muara Bangkahulu Kota Bengkulu. 
Tabel 3. Hasil Angket Evaluasi Kegiatan Pengabdian Pembuatan Lampu Hias Akrilik 3D Led

\begin{tabular}{|c|c|c|c|c|c|c|c|c|c|c|c|c|c|c|}
\hline \multirow{2}{*}{$\begin{array}{c}\text { No } \\
\text { Responden }\end{array}$} & \multicolumn{14}{|c|}{ Pertanyaan Soal } \\
\hline & $\mathrm{S}_{1}$ & $\mathrm{~S}_{2}$ & $\mathrm{~S}_{3}$ & $\mathrm{~S}_{4}$ & $\mathrm{~S}_{5}$ & $\mathrm{~S}_{6}$ & $\mathrm{~S}_{7}$ & $\mathrm{~S}_{8}$ & $\mathrm{~S}_{9}$ & $\mathrm{~S}_{10}$ & $S_{11}$ & $\mathrm{~S}_{12}$ & $S_{13}$ & $\begin{array}{l}\text { Total } \\
\text { Soal }\end{array}$ \\
\hline 1 & 4 & 4 & 4 & 4 & 4 & 4 & 4 & 4 & 4 & 4 & 4 & 4 & 4 & 52 \\
\hline 2 & 3 & 3 & 3 & 3 & 3 & 3 & 3 & 4 & 4 & 4 & 4 & 4 & 4 & 45 \\
\hline 3 & 4 & 4 & 3 & 4 & 3 & 4 & 4 & 4 & 4 & 3 & 4 & 4 & 4 & 49 \\
\hline 4 & 3 & 3 & 3 & 3 & 3 & 3 & 3 & 3 & 3 & 3 & 3 & 3 & 3 & 39 \\
\hline 5 & 3 & 4 & 3 & 4 & 3 & 3 & 3 & 4 & 4 & 4 & 3 & 4 & 4 & 46 \\
\hline 6 & 3 & 4 & 3 & 3 & 3 & 3 & 3 & 4 & 4 & 4 & 4 & 4 & 4 & 46 \\
\hline 7 & 4 & 4 & 4 & 4 & 4 & 4 & 4 & 4 & 4 & 4 & 3 & 3 & 3 & 49 \\
\hline 8 & 4 & 4 & 4 & 4 & 4 & 4 & 4 & 4 & 4 & 4 & 4 & 4 & 4 & 52 \\
\hline 9 & 4 & 4 & 4 & 4 & 4 & 4 & 4 & 4 & 4 & 3 & 4 & 4 & 4 & 51 \\
\hline 10 & 3 & 4 & 4 & 4 & 4 & 4 & 4 & 4 & 4 & 4 & 4 & 4 & 4 & 51 \\
\hline $\mathrm{R}_{\text {Hitung }}$ & 0.67 & 0.77 & 0.8 & 0.8 & 0.8 & 0.8 & 0.84 & 0.8 & 0.8 & 0.3 & 0.6 & 0.5 & 0.5 & 1 \\
\hline $\mathrm{R}_{\text {Tabel }}$ & 0.55 & 0.55 & 0.6 & 0.6 & 0.6 & 0.6 & 0.55 & 0.6 & 0.6 & 0.6 & 0.6 & 0.6 & 0.6 & 0.55 \\
\hline $\mathrm{V} / \mathrm{T}$ & $\mathrm{V}$ & $\mathrm{V}$ & $\mathrm{V}$ & $\mathrm{V}$ & $\mathrm{V}$ & $\mathrm{V}$ & $\mathrm{V}$ & $\mathrm{V}$ & $\mathrm{V}$ & $\mathrm{T}$ & $\mathrm{V}$ & $\mathrm{T}$ & $\mathrm{T}$ & $\mathrm{V}$ \\
\hline
\end{tabular}

Keterangan : Data dikatakan "Valid" jika $\mathrm{R}_{\text {hitung }}$ lebih besar dari $\mathrm{R}_{\text {Tabel }}$

$$
\begin{aligned}
& \mathrm{V}=\text { Valid } \\
& \mathrm{T}=\text { Tidak Valid }
\end{aligned}
$$

Hasil gambar papan kayu yang sudah di potong dan papan kayu yang sudah di bungkus menggunakan kertas pembungkus bisa dilihat pada gambar 5 di bawah ini.

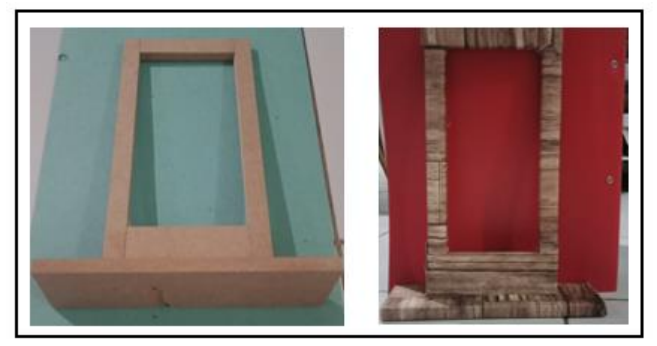

Gambar 4. Papan Yang Siap Digunakan Untuk Lampu Hias

Dari alat dan bahan serta langkah-lah pembuatan lampu hias akrilik 3D Led didapat hasil produk seperti pada gambar 6 di bawah ini. 


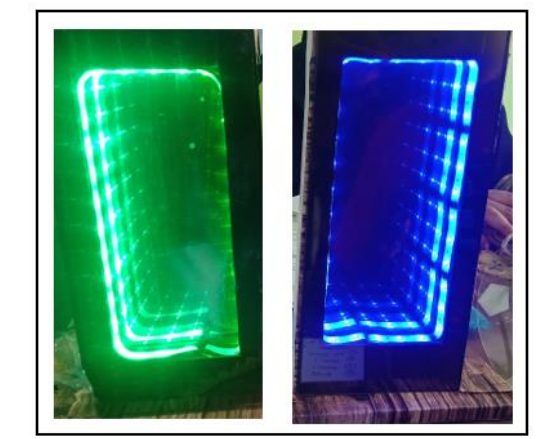

Gambar 5. Lampu Hias Akrilik 3D Led

\section{Diskusi}

Dari tinjauan pustaka terdahulu oleh (Sungkowo Damar, 2016) bahan dari lampu hias yang digunakan adalah limbah kayu Jati, limbah kayu Nangka, limbah kayu Mahoni dan beberapa limbah kayu campuran, hasil dari penciptaan karya lampu hias ini adalah lampu hias Bhuvarloka, Kala Bubrah, Kala Sumringah, Lingga-Yoni, Padma, Nandi Padmasana dan Ganesha. Menurut (Claudia \& Setiawan, 2017) desain lampu hias juga mengalami kemajuan dengan adanya perkembangan teknologi, saat ini lampu tidak hanya berfungsi sebagai penerang tetapi juga dapat digunakan sebagai elemen dekorasi dalam desain interior maupun exterior. Menurut (Bangun \& Silaban, 2017) yang mana hasil penelitiannya adalah lampu hias terbuat dari kayu yang diukir.

Pemanfaatan limbah akrilik menjadi produk fesyen aksesoris dengan teknik pemanasan ini cukup menghasilkan inovasi dalam pengembangan produk fesyen. Selain itu, pemanfaatan limbah akrilik dapat mengurangi penceramaran lingkungan pada industri akrilik (Girsang \& Wahmuda, 2018). Selain itu menurut (Artono \& Putra, 2018) lampu hias juga terbuat dari paralon yang dipotong. Menurut (Hasan, 2018) lampu hias juga bisa terbuatan dari bahan anyaman bambu. Menurut (Hasan \& Chairuddin, 2019) mengemukakan pendapatnya yaitu lampu hias juga bisa terbuat dari bambu yang diukir, lalu lampu hias juga bisa dibuat dari bahan dasar logam dengan tema burung engga bisa juga dengan tema yang berbeda hal ini menurut (Al Amin, 2018), begitu juga pendapat (Manalu \& Mesra, 2019) lampu hias terbuat dari batok kelapa yang diukir. Dan tahun 2020 saya berharap akrilik sebagai bahan dasar 
pembuatan lampu hias yang elegan sesuai dengan permintaan pasar sehingga bisa meningkatkan pendapatan semua kalangan masyarakat di Indonesia dan lebih khususnya di Jl. Korpri Raya RT. 10 RW. 03 Kelurahan Bentiring Kecamatan Muara Bangkahulu Kota Bengkulu.

\section{Kesimpulan}

Bahwa pelaksanaan pelatihan pembuatan lampu hias akrilik 3D di Kota Bengkulu, didapatkan hasil yang sesuai dengan harapan yaitu :

1. Peserta sudah memahami materi pelatihan sesuai dengan Tabel 1. Hasil Angket Evaluasi Kegiatan Pengabdian Pembuatan Lampu Hias Akrilik 3D Led.

2. Peserta sudah dapat menyelesaikan perakitan lampu hias.

\section{Pengakuan/Acknowledgements}

Penulis mengucapkan terima kasih kepada Lembaga Penelitian dan Pengabdian Kepada Masyarakat Universitas Bengkulu yang telah memberi dukungan financial terhadap pengabdian ini dengan Nomor : SP DIPA023.017.2.677529/2020 Tanggal 27 Desember 2019 sesuai dengan Kontrak Perjanjian Nomor :2377/UN30.15/AM/2020.

\section{Daftar Referensi}

Al Amin, A. (2018). Burung enggang dalam lampu hias [Institut Seni Indonesia Yogyakarta]. http://digilib.isi.ac.id/5424/

Artono, B., \& Putra, R. G. (2018). Pelatihan dan pembuatan internet of things untuk lampu hias ruang tamu dengan bahan paralon bekas di kelurahankedungbunder, kecamatan sutojayan kabupaten blitar, propinsi jawa timur. J-ADIMAS (Jurnal Pengabdian Kepada Masyarakat), 6(2), 63-69.

https://jurnal.stkippgritulungagung.ac.id/index.php/jadimas/article/view/ $883 / 389$

Bangun, N. B., \& Silaban, B. (2017). Analisis Cenderamata Kerajinan Ukir Kayu Di Pasar Buah Berastagi Ditinjau Dari Prinsip-Prinsip Desain. Gorga Jurnal Seni Rupa, 6(2). https://doi.org/10.24114/gr.v6i2.7009

Claudia, R. K., \& Setiawan, A. P. (2017). Perancangan Kap Lampu Hias 
dengan Material Tembus Cahaya. Jurnal Intra, 5(2), 798-801. http://publication.petra.ac.id/index.php/desain-interior/issue/view/243

Girsang, H. S. D., \& Wahmuda, F. (2018). Eksperimen Produk Fungsional limbah Akrilik dengan Teknik Pemanasan dalam Penerapan Desain Fesyen Aksesoris. Prosiding Seminar Nasional Sains ..., 465-470. https://ejurnal.itats.ac.id/sntekpan/article/view/327

Hasan, B. (2018). Manajeman Produksi Usaha Lampu Hias Kreasi Bamboo di Kabupaten Bangkalan Propinsi Jawa Timur. JAST : Jurnal Aplikasi Sains Dan Teknologi, 2(2), 88. https://doi.org/10.33366/jast.v2i2.1115

Hasan, B., \& Chairuddin, C. (2019). Pengembangan Usaha Lampu Hias Rumah Ukir Bambu Di Kabupaten Bangkalan. Jurnal Terapan Abdimas, 4(2), 152. https://doi.org/10.25273/jta.v4i2.4805

Manalu, A., \& Mesra, M. (2019). Analisis Analisis Produk Kerajinan Lampu Hias Dari Batok Kelapa Pada Perajin Wak Jek Art (Wja) Di Medan Ditinjau Dari Bentuk. Gorga: Jurnal Seni Rupa, 8(1), 267. https://doi.org/10.24114/gr.v8i1.13638

Sejarah Kota Bengkulu - Website Resmi Profil | Pemerintah Kota Bengkulu. (2020). https://profil.bengkulukota.go.id/sejarah-kota-bengkulu/

Sungkowo Damar. (2016). Ornamen Candi Ijo Sebagai Dekorasi Pada Lampu Hias Candi Ijo Ornamenst Aa Decorations On Decorative Lamps Made Of Wooden. Pendidikan Seni Kerajinan, Pendidikan Seni Rupa, 1(1), 110. http://eprints.uny.ac.id/id/eprint/29912 